\title{
Gender differences in relation to hyperuricemia and nonalcoholic fatty liver disease among Type 2 diabetics in Telangana, India
}

\author{
Usha Sree Puneem $^{\mathrm{a}, \mathrm{b}, \mathrm{c}}$, Subburaya Mudaliyar Rajendran Ramakrishnan ${ }^{\mathrm{d}}$, \\ Vasudeva Murthy Sindgi ${ }^{c}$, Vanitha Rani Nagasubramanian ${ }^{\text {a, }}$ \\ ${ }^{a}$ Department of Pharmacy Practice, Sri Ramachandra Institute of Higher Education \& Research, Deemed to be University, Porur, Chennai, 600116, Tamil Nadu, India \\ ${ }^{\mathrm{b}}$ Department of Gastroenterology, Bhargavi Bhargavi gastro and surgical clinic, Warangal, Telangana, India \\ ${ }^{c}$ Department of Pharmacy Practice, Jayamukhi College of Pharmacy, Narasampet, Warangal, 506332, Telangana, India \\ ${ }^{\mathrm{d}}$ Department of General Medicine, Sri Ramachandra Institute of Higher Education and Research Deemed to be University, Porur, Chennai, 600116, Tamil Nadu, India
}

\section{A R T I C L E I N F O}

\section{Keywords:}

Serum uric acid

NAFLD

Type-2 diabetes

Gender difference

\begin{abstract}
A B S T R A C T
Background: Scarcity of data in relationship between hyperuricemia and nonalcoholic fatty liver disease (NAFLD) in Type 2 diabetics (T2DM), particularly in terms of gender differences. Hence, the study was aimed to investigate the gender difference in association between hyperuricemia, and NAFLD in the Indian population. Methodology: A cross-sectional study was conducted with 134 Indian adults, of which 93 males and 41were females. Among them hyperurecemics are $66(71 \%)$ males and $26(63 \%)$ are females. The sample was collected at the department of gastroenterology. The student t-test was applied to assess the risk of hyper and nonhyperuricemia among the NAFLD in Type-2 diabetics. Pearson correlation was used to assess link between serum uric acid and other biochemical parameters.

Results: The BMI, SGOT, ALP and LDL levels are significantly elevated in hyperuricemia male subjects $(\mathrm{P}<0.05)$. Triglyceride levels had a weak negative correlation with serum uric acid (SUA) levels, which was significant in male NAFLD subjects (P 0.01). The overall prevalence of hyperuricemia was more in males as compared with females $(\mathrm{P}<0.05)$.

Conclusion: Our results reveal that the dyslipidemia is more closely associated with hyperuricemia in men than women with NAFLD. Total cholesterol and Triglycerides showed significant weak negative correlation with SUA in males. Further longitudinal studies are required to prove these findings.
\end{abstract}

\section{Introduction}

Non-alcoholic fatty liver disease (NAFLD) is a divergent hepatobiliary disorder that is one of the leading causes of chronic liver disease worldwide. The disease's prevalence in the general Indian population is estimated to be $9-32 \%{ }^{1}$ with obese and diabetic patients having a higher incidence rate. Metabolic syndrome and associated co-morbidities such as type 2 diabetes (T2DM), obesity, and dyslipidemia are risk factors for NAFLD, and the prevalence of NAFLD has risen in tandem with these epidemics. ${ }^{2,3}$

Serum uric acid (SUA) level greater than $7.0 \mathrm{mg} / \mathrm{dL}$ in men and greater than $5.7 \mathrm{mg} / \mathrm{dL}$ in women was considered to be hyperuricemia and it is an independent risk factor for hypertension, diabetes, metabolic syndrome, CKD, and cardiovascular events. ${ }^{4,5}$ The rising prevalence of hyperuricemia is regarded as a new public health concern. Many factors, including dietary and lifestyle changes, excess weight, population ageing, and increased antihypertensive drug prescription, may increase the risk of hyperuricemia. A number of studies have found a link between hyperuricemia and NAFLD, with elevated UA levels increasing the prevalence of NAFLD. ${ }^{6,7}$ However, the link between gender-specific hyperuricemia in NAFLD and Type 2 diabetes were not well understood. Hence, were aimed to explore the link between the hyperuricemia in NAFLD with Type-2 diabetes.

\section{Materials and methods}

A cross-sectional study conducted at department of gastroenterology, Bhargavi gastro and surgical clinic Warangal, between January 2020

\footnotetext{
* Corresponding author. Faculty of Pharmacy, Department of Pharmacy Practice, Sri Ramachandra Institute of Higher Education \& Research, Deemed to be University, Porur, Chennai, 600116, Tamil Nadu, India. Tel.: +91-9444584588.

E-mail address: vanitharani.n@sriramachandra.edu.in (V.R. Nagasubramanian).
} 
and March 2021 with eligible criteria. Tto he study subjects were included based on the inclusion and exclusion criteria.

\subsection{Inclusion of subjects with NAFLD}

Patients with history of type 2 diabetes mellitus and were subjected to ultrasonography. NAFLD was diagnosed based on histological or imaging findings, and subjects with no history of alcohol consumption were included in the study.

\subsection{Exclusion criteria}

Subjects were excluded based on the following criteria were excluded: alcohol consumption $>140 \mathrm{~g} /$ week for men and $70 \mathrm{~g} /$ week for women, lipid-lowering, or anti hyperuricemic agents, any other known potential causes of chronic liver disease such as viral or autoimmune hepatitis and those using hepatotoxic medications; subjects with history of cancer, respiratory, renal, or hepatobiliary disease, gout, and other rheumatologic diseases. Type 1 diabetes, gestational diabetes, or acute complications of diabetes. All study participants provided informed written consent prior to participate in the study.

\subsection{Laboratory examinations}

Fasting blood samples obtained from each subject were used for the analysis of biochemical parameters. The parameters assessed include fasting plasma glucose (FBS),serum uric acid (SUA), total proteins, albumin (A), globulin(G), A/G ratio, serum glutamate pyruvate transaminase (SGPT), serum glutamate oxaloacetate transaminase ((SGOT), SGOT:SGPT ratio, alkaline phosphates, nitrogenous end product-blood urea nitrogen (BUN), serum creatinine ( $\mathrm{Cr}$ ), and fasting lipid profiles that comprise of triglyceride (TG), total cholesterol (TC), low-density lipoprotein cholesterol (LDL-C) and high-density lipoprotein cholesterol. All the biochemical parameters were analyzed through standard protocols with the aid of automated immunochemical analyzer (Abbott AxSYM).

\subsection{Statistical analysis}

All statistical analyses were performed using IBM SPSS 20 (SPSS, Chicago, Illinois, USA) statistical package for windows. Continuous variables were compared using the Student's $t$-test or the Mann-Whitney $U$ test, depending on the normality of distribution, whereas the relationships between SUA and other metabolic risk variables were assessed using Pearson's correlations. Any value of $\mathrm{p}<0.05$ was considered statistically significant.

\section{Results}

The study included 134 subjects with Type 2 diabetes who had NAFLD, of which 93 males (69\%) and 41 females (31\%). The data were collected at the outpatient department of Bhargavi gastro and surgical clinic, Hanamkonda, Warangal, Telangana. The study was conducted during the period of 2019 and 2021. Table 1 show that male subjects have a higher BMI, higher levels of liver enzymes (SGOT and SGPT) than females, which is statistically significant $(\mathrm{P}<0.05)$. The remaining demographic and biochemical parameters are not significant among the subjects. Table 2 illustrated the association between gender and hyperuricemia among the Type-2 NAFLD subjects. The mean and SD values of BMI, SGOT, ALP and LDL levels are higher in male NAFLD subjects compared to females. The mean difference was statistically significant.

The male subjects were having higher mean values for body weight, FBS, liver enzymes, and serum uric acids. Despite all are having NAFLD, male subjects SUA levels were borderline elevated. SUA are normal in female subjects with NAFLD. These findings suggest that SUA levels play no role in the development of NAFLD in Type 2 diabetics (Table 3). The
Table 1

Gender wise distribution of demographic and clinical characteristics of study subjects.

\begin{tabular}{|c|c|c|c|}
\hline \multirow[t]{2}{*}{ Variables } & \multirow{2}{*}{$\begin{array}{l}\text { Male }(\mathrm{n}=93 \\
69 \%) \\
\text { Mean } \pm \text { SD }\end{array}$} & \multirow{2}{*}{$\begin{array}{l}\text { Female }(\mathrm{n}= \\
41,31 \%) \\
\text { Mean } \pm \mathrm{SD}\end{array}$} & \multirow[t]{2}{*}{$p$ value } \\
\hline & & & \\
\hline Age & $46.6 \pm 7.605$ & $47.46 \pm 8.24$ & 0.753 \\
\hline \multicolumn{4}{|l|}{ Marital status $\dagger$} \\
\hline Married (n,\%) & $60(87)$ & $38(93)$ & 0.311 \\
\hline Unmarried (n,\%) & 09 (13) & $03(07)$ & \\
\hline \multicolumn{4}{|l|}{ Level of study $\dagger$} \\
\hline Illiterates (n,\%) & $15(16)$ & $09(22)$ & 0.404 \\
\hline $10+2$ and above $(n, \%)$ & $78(84)$ & $32(78)$ & \\
\hline $\begin{array}{l}\text { Duration of Diabetes } \\
\text { (yrs) }\end{array}$ & $4.57 \pm 2.35$ & $4.58 \pm 1.99$ & 0.882 \\
\hline Height (mts) & $1.637 \pm 0.08$ & $1.621 \pm 0.09$ & 0.245 \\
\hline Body Weight(kg) & $61.69 \pm 8.41$ & $54.73 \pm 6.5$ & $<0.0001^{* * *}$ \\
\hline BMI $\left(\mathrm{Kg} / \mathrm{m}^{2}\right)$ & $22.51 \pm 3.03$ & $21.21 \pm 2.38$ & $0.0163^{*}$ \\
\hline $\begin{array}{l}\text { Waist Circumference } \\
(\mathrm{cm})\end{array}$ & $90.56 \pm 4.99$ & $90.84 \pm 7.96$ & 0.804 \\
\hline FBS $(\mathrm{mg} / \mathrm{dl})$ & $111.8 \pm 26.98$ & $108 \pm 27.88$ & 0.183 \\
\hline SGOT (u/l) & $48.15 \pm 41.34$ & $30.09 \pm 13.76$ & $0.0003 * * *$ \\
\hline SGPT $(\mathrm{u} / \mathrm{l})$ & $69.72 \pm 62.7$ & $46.11 \pm 23.73$ & $0.0055 * *$ \\
\hline SGOT:SGPT & $0.76 \pm 0.36$ & $0.77 \pm 0.62$ & 0.204 \\
\hline ALP mg/dl & $88.53 \pm 32.27$ & $80.07 \pm 26.9$ & $0.0384 *$ \\
\hline Total Proteins $(\mathrm{gm} / \mathrm{dl})$ & $6.99 \pm 0.83$ & $6.99 \pm 0.48$ & 0.746 \\
\hline $\operatorname{Albumin}(\mathrm{gm} / \mathrm{dl})$ & $3.62 \pm 0.42$ & $3.62 \pm 0.50$ & 0.874 \\
\hline Globulin(gm/dl) & $3.438 \pm 0.43$ & $3.33 \pm 0.40$ & 0.181 \\
\hline $\mathrm{A} / \mathrm{g}$ ratio & $1.072 \pm 0.22$ & $1.09 \pm 0.24$ & 0.869 \\
\hline $\begin{array}{l}\text { Serum Creatinine (mg/ } \\
\text { dl) }\end{array}$ & $0.94 \pm 0.36$ & $0.89 \pm 0.31$ & 0.248 \\
\hline Blood urea(mg/dl) & $23.77 \pm 6.29$ & $22.57 \pm 4.57$ & 0.068 \\
\hline SUA (mg/dl) & $7.53 \pm 1.16$ & $7.056 \pm 1.76$ & 0.067 \\
\hline $\mathrm{TC}(\mathrm{mg} / \mathrm{dl})$ & $205.6 \pm 43.91$ & $197.3 \pm 33.98$ & 0.206 \\
\hline LDL (mg/dl) & $145.6 \pm 32.29$ & $136.4 \pm 27.55$ & 0.062 \\
\hline $\mathrm{HDL}$ (mg/dl) & $45.97 \pm 22.99$ & $47.37 \pm 26.11$ & 0.933 \\
\hline $\mathrm{TG}(\mathrm{mg} / \mathrm{dl})$ & $176.9 \pm 30.46$ & $175.3 \pm 21.62$ & 0.801 \\
\hline
\end{tabular}

P value $<0.05$ was considered to be statistically significant.

Table 2

Association of hyperuricemia among the study the subjects.

\begin{tabular}{|c|c|c|c|}
\hline \multirow[t]{3}{*}{ Variables } & \multicolumn{2}{|c|}{ Hyperuricemic subjects $(\mathrm{N}=92)$} & \multirow[t]{3}{*}{$p$ value } \\
\hline & $\operatorname{Male}(\mathrm{n}=66)$ & Female $(\mathrm{n}=26)$ & \\
\hline & Mean \pm SD & Mean \pm SD & \\
\hline Age & $47.71 \pm 7.88$ & $47.88 \pm 9$ & 0.898 \\
\hline Height (mts) & $1.64 \pm 0.07$ & $1.63 \pm 0.07$ & 0.527 \\
\hline Body Weight(kg) & $65.18 \pm 7.193$ & $58.69 \pm 7.16$ & $0.0017 * *$ \\
\hline BMI $\left(\mathrm{Kg} / \mathrm{m}^{2}\right)$ & $24.38 \pm 4.01$ & $22.19 \pm 3.81$ & $0.0468 *$ \\
\hline Waist Circumference $(\mathrm{cm})$ & $91.02 \pm 4.7$ & $90.52 \pm 7.98$ & 0.456 \\
\hline Duration of Diabetes (yrs) & $4.86 \pm 2.36$ & $4.55 \pm 1.95$ & 0.735 \\
\hline FBS (mg/dl) & $116.85 \pm 35.19$ & $115.19 \pm 31.38$ & 0.864 \\
\hline SGOT $(\mathrm{u} / \mathrm{l})$ & $51.1 \pm 46.09$ & $33.16 \pm 16.4$ & $0.0101 *$ \\
\hline SGPT $(u / 1)$ & $73.3 \pm 71.18$ & $49.27 \pm 29.23$ & 0.107 \\
\hline $\operatorname{ALP}(\mathrm{u} / \mathrm{l})$ & $91.11 \pm 31.8$ & $83.06 \pm 33.68$ & $0.0388 *$ \\
\hline Total Proteins(gm/dl) & $7.08 \pm 0.56$ & $6.95 \pm 0.51$ & 0.309 \\
\hline Albumin(gm/dl) & $3.57 \pm 0.42$ & $3.55 \pm 0.51$ & 0.973 \\
\hline Globulin(gm/dl) & $3.49 \pm 0.39$ & $3.37 \pm 0.39$ & 0.147 \\
\hline $\mathrm{A} / \mathrm{g}$ ratio & $1.04 \pm 0.19$ & $1.06 \pm 0.23$ & 0.900 \\
\hline Serum Creatinine (mg/dl) & $0.94 \pm 0.38$ & $0.89 \pm 0.35$ & 0.419 \\
\hline Blood urea $(\mathrm{mg} / \mathrm{dl})$ & $24.21 \pm 6.87$ & $22.92 \pm 4.73$ & 0.140 \\
\hline SUA (mg/dl) & $8.08 \pm 0.79$ & $8.15 \pm 1.18$ & 0.440 \\
\hline $\mathrm{TC}(\mathrm{mg} / \mathrm{dl})$ & $209.68 \pm 42.89$ & $201.84 \pm 36.87$ & 0.379 \\
\hline LDL (mg/dl) & $149.12 \pm 31.93$ & $134.5 \pm 29.11$ & $0.0386^{*}$ \\
\hline HDL (mg/dl) & $46.63 \pm 24.11$ & $51.65 \pm 25.8$ & 0.438 \\
\hline $\mathrm{TG}(\mathrm{mg} / \mathrm{dl})$ & $179.07 \pm 32.26$ & $174.5 \pm 26.14$ & 0.413 \\
\hline
\end{tabular}

P value $<0.05$ was considered to be statistically significant.

proportion of hyperuricemia was high $(\mathrm{N}=66,71 \%)$ in male subjects as compared to females and which was statistically significant $(\mathrm{P}<0.05)$ (Table 4).

Table 5 shows the relationship between SUA and other variables. According to the findings in Table 5, nearly all variables are negatively 
Table 3

Gender wise association of Non-hyperuricemia among the study the subjects.

\begin{tabular}{|c|c|c|c|}
\hline \multirow[t]{3}{*}{ Variables } & \multicolumn{2}{|c|}{ Non-Hyperuricemic subjects $(\mathrm{N}=42)$} & \multirow[t]{3}{*}{$p$ value } \\
\hline & Male $(\mathrm{n}=27)$ & Female $(\mathrm{n}=15)$ & \\
\hline & Mean \pm SD & Mean \pm SD & \\
\hline Age & $44.62 \pm 5.42$ & $46.73 \pm 6.94$ & 0.316 \\
\hline Height (mts) & $1.62 \pm 0.09$ & $1.59 \pm 0.10$ & 0.298 \\
\hline Body Weight(kg) & $61.96 \pm 7.48$ & $53.4 \pm 6.10$ & $0.0003^{* * *}$ \\
\hline $\mathrm{BMI}\left(\mathrm{Kg} / \mathrm{m}^{2}\right)$ & $23.61 \pm 3.44$ & $21.49 \pm 1.38$ & 0.120 \\
\hline Waist Circumference $(\mathrm{cm})$ & $89.45 \pm 5.57$ & $91.38 \pm 8.18$ & 0.627 \\
\hline Duration of Diabetes (yrs) & $3.88 \pm 2.2$ & $4.63 \pm 2.14$ & 0.269 \\
\hline FBS (mg/dl) & $114.65 \pm 40.26$ & $94.61 \pm 11.82$ & $0.0108 *$ \\
\hline SGOT (u/l) & $38.93 \pm 23.94$ & $24.74 \pm 3.46$ & $0.0462 *$ \\
\hline SGPT $(\mathrm{u} / \mathrm{l})$ & $57.55 \pm 31.22$ & $40.62 \pm 5.62$ & $0.0211^{*}$ \\
\hline $\operatorname{ALP}(\mathrm{u} / \mathrm{l})$ & $81.96 \pm 33.14$ & $75.08 \pm 5.31$ & 0.752 \\
\hline Total Proteins(gm/dl) & $6.8 \pm \overline{1.26}$ & $7.06 \pm 0.45$ & 0.356 \\
\hline $\operatorname{Albumin}(\mathrm{gm} / \mathrm{dl})$ & $3.73 \pm 0.43$ & $3.76 \pm 0.48$ & 0.921 \\
\hline Globulin(gm/dl) & $3.29 \pm 0.48$ & $3.26 \pm 0.42$ & 0.963 \\
\hline $\mathrm{A} / \mathrm{G}$ ratio & $1.14 \pm 0.27$ & $1.15 \pm 0.24$ & 0.974 \\
\hline Serum Creatinine (mg/dl) & $0.96 \pm 0.31$ & $0.88 \pm 0.21$ & 0.369 \\
\hline Blood urea(mg/dl) & $22.68 \pm 4.49$ & $21.89 \pm 4.35$ & 0.263 \\
\hline SUA (mg/dl) & $6.2 \pm 0.77$ & $5.14 \pm 0.51$ & $<0.0001^{* * * *}$ \\
\hline $\mathrm{TC}(\mathrm{mg} / \mathrm{dl})$ & $195.77 \pm 45.6$ & $189.46 \pm 27.69$ & 0.470 \\
\hline LDL (mg/dl) & $137.11 \pm 32.14$ & $139.6 \pm 25.24$ & 0.691 \\
\hline HDL (mg/dl) & $44.33 \pm 20.28$ & $39.93 \pm 25.78$ & 0.478 \\
\hline $\mathrm{TG}(\mathrm{mg} / \mathrm{dl})$ & $171.7 \pm 25.28$ & $176.8 \pm 10.56$ & 0.202 \\
\hline
\end{tabular}

$\mathrm{P}$ value $<0.05$ was considered to be statistically significant.

Table 4

Association of Hyperuricemia among the male and female gender with NAFLD.

\begin{tabular}{llll}
\hline Parameter & Male $(\mathrm{N}=93)(\%)$ & Female $(\mathrm{N}=41)(\%)$ & $p$ value \\
\hline Hyperuricemia & $66(71)$ & $26(63)$ & $<0.0001^{* * *}$ \\
Non- Hyperuricemia & $27(29)$ & $15(37)$ & 0.0193 \\
\hline
\end{tabular}

$\mathrm{P}$ value $<0.05$ was considered to be statistically significant.

Table 5

Pearson bivariate correlations between serum uric acid and other variables in male and female subjects.

\begin{tabular}{|c|c|c|c|c|}
\hline \multirow[t]{2}{*}{ Variables } & \multicolumn{2}{|l|}{ Males } & \multicolumn{2}{|l|}{ Females } \\
\hline & $\mathrm{r}$ & $\mathrm{p}$ & $\mathrm{r}$ & $\mathrm{P}$ \\
\hline Height (mts) & -0.078 & 0.534 & -0.35 & 0.08 \\
\hline Body Weight(kg) & -0.085 & 0.567 & -0.159 & 0.437 \\
\hline BMI $\left(\mathrm{Kg} / \mathrm{m}^{2}\right)$ & 0.019 & 0.877 & 0.085 & 0.68 \\
\hline Waist Circumference (cm) & -0.036 & 0.778 & -0.24 & 0.248 \\
\hline FBS (mg/dl) & -0.033 & 0.791 & -0.176 & 0.389 \\
\hline SGOT (u/l) & -0.068 & 0.588 & -0.112 & 0.585 \\
\hline SGPT (u/l) & -0.105 & 0.401 & -0.111 & 0.591 \\
\hline $\mathrm{TC}(\mathrm{mg} / \mathrm{dl})$ & $-0.245^{*}$ & 0.048 & -0.346 & 0.084 \\
\hline $\mathrm{LDL}(\mathrm{mg} / \mathrm{dl})$ & -0.193 & 0.121 & -0.317 & 0.114 \\
\hline HDL (mg/dl) & -0.151 & 0.225 & -0.191 & 0.351 \\
\hline TG (mg/dl) & $-.315^{* *}$ & 0.01 & -0.267 & 0.187 \\
\hline
\end{tabular}

$\mathrm{P}$ value $<0.05$ was considered to be statistically significant.

correlated with SUA, particularly the week negative correlation. Triglyceride levels had a weak negative correlation with SUA levels, which was significant in male NAFLD patients (P 0.01).

\section{Discussion}

In our study, we noticed that the prevalence of hyperuricemia is high in male NAFLD patients with Type 2 diabetes. The findings also revealed that the link between hyperuricemia and NAFLD was significantly stronger in men than in women. In contrast, obesity or being overweight is one of the factors that cause of hyperuricemia in men. ${ }^{8,9}$ The onset of NAFLD is complicated and still poorly understood. Many risk factors, including genetic, metabolic, and dietary factors, are thought to play a role in the development of NAFLD. ${ }^{10}$ Liver cell damage was observed in NALFD, particularly in Type-2 diabetics. Liver enzymes such as SGOT were found to be impaired. ${ }^{11}$ In this study, males had significantly higher mean values of liver enzymes than females. Similarly, an association was observed with alkaline phosphataes.ALP is found in various body tissues and has varying physiochemical properties. ALP is an enzyme that is elevated by a variety of hepatobiliary diseases or bone disorders. ${ }^{12}$ In our study, male subjects had significantly higher ALP levels. Similarly, Chen et al. were confirmed in a prospective study, stating that increased levels of ALP are one of the risk factors in Type 2 diabetics. ${ }^{13}$ In NAFLD hyperurecemic diabetic patients, an elevated BMI is also a risk factor. Males have a higher BMI than females in our study. Increased BMI may likely to cause depression. ${ }^{14}$ Dyslipidemia is a major contributor to the development of NAFLD. ${ }^{15}$ A $20-80 \%$ of NAFLD cases were having, hypertriglyceridemia, low HDL-C levels, and high low-density lipoprotein cholesterol (LDL-C) levels respectively. According to Marchesini et al., hypertriglyceridemia is also present in $64 \%$ of patients with hepatic steatosis, with low HDL-C levels reported in $30-42 \%$ of cases. ${ }^{16}$

In our study, hyperuricemic subjects had elevated TG and LDL cholesterol. A significant association with high lipid levels and hyperuricemia was noticed in male subjects. Non-hyperuricemic subjects had borderline LDL cholesterol and high TG levels. These findings clearly demonstrated that elevated triglycerides were strongly associated with NALFD. Our Pearson bivariate analysis confirmed that, the serum uric acid levels and triglyceride levels were found to have a significant negative weak correlation among Type-2 diabetic NAFLD subjects.

\subsection{Strengths and limitations}

The current research has both benefits and weaknesses. To our knowledge, this is the first research in Telangana, India, to investigate the relationship between hyperuricemia and NAFLD in Type- 2 diabetics. In terms of gender, our results support the links between hyperuricemia and NAFLD. Additionally, in our study, we have not seen any confounders; hence, we have not adjusted for confounding variables in our analyses. As a result, further longitudinal research is required to prove these findings. Hence, the conclusions may not be generalized to the population in the whole India.

\section{Conclusion}

Our findings demonstrate, dyslipidemia is more closely associated with hyperuricemia in men than women with NAFLD. Particularly, total cholesterol and triglycerides are showed significant weak negative correlation with SUA in males. Further longitudinal studies are needed to confirm these findings to establish the role of uric acid in the pathogenesis of NAFLD in Type- 2 diabetics.

\section{Author contributions}

Concept- VR.N; Design-SR.R VS.M; Supervision-VS.M; Materials Data Collection and/or Processing-US.P; Analysis and/or InterpretationVR.N., US.P., VS.M; Literature Search-US.P,; Writing-US.P., VR.N.; Critical Reviews-VR.N, SR.K,VS.M.

\section{Source of funding}

Self funded study.

\section{Compliance with ethical standards}

The study procedure was approved by the Institutional Ethics Committee, Dated:10.12.2019 (IEC/19/Nov/71/10) of Sri Ramachandra Institute of Higher Education and Research (Deemed to be University), Chennai and has affiliation with Bhargavi gastro and surgical clinic 
Warangal, Telangana, India, and the research was carried out in conjunction with Good clinical practice guidelines.

\section{Declaration of competing interest}

Authors declare that they have no conflict of interest.

\section{Acknowledgement}

Authors are thankful to department of bhargavi gastroenterology, Hanmakonda, Telagana, India.

\section{References}

1 Atri A, Jiwanmall SA, Nandyal MB, et al. The prevalence and predictors of nonalcoholic fatty liver disease in morbidly obese women-A cross-sectional study from Southern India. Eur Endocrinol. 2020 Oct;16(2):152 ([CrossReff]).

2 Kalra S, Vithalani M, Gulati G, et al. Study of prevalence of nonalcoholic fatty liver disease (NAFLD) in type 2 diabetes patients in India (SPRINT). J Assoc Phys India. 2013 Jul 1;61(7):448-453 [PMID: 24772746].

3 Bugianesi E, Vanni E, Marchesini G. NASH and the risk of cirrhosis and hepatocellular carcinoma in type 2 diabetes. Curr Diabetes Rep. 2007 Jun 1;7(3): 175-180 ([CrossReff]).

4 Oh TR, Choi HS, Kim CS, et al. Hyperuricemia has increased the risk of progression of chronic kidney disease: propensity score matching analysis from the KNOW-CKD study. Sci Rep. 2019 Apr 30;9(1):1-9 ([CrossReff]).

$5 \mathrm{Li}$ LX, Dong XH, Li MF, et al. Serum uric acid levels are associated with hypertension and metabolic syndrome but not atherosclerosis in Chinese inpatients with type 2 diabetes. J Hypertens. 2015 Mar;33(3):482 ([CrossReff]).
6 Huang Q, Yu J, Zhang X, Liu S, Ge Y. Association of the serum uric acid level with liver histology in biopsy-proven non-alcoholic fatty liver disease. Biomedical reports. 2016 Aug 1;5(2):188-192 ([CrossReff]).

7 Yu S, Yang H, Guo X, et al. Prevalence of hyperuricemia and its correlates in rural Northeast Chinese population: from lifestyle risk factors to metabolic comorbidities. Clin Rheumatol. 2016 May 1;35(5):1207-1215 ([CrossReff]).

8 Chen Y, Zhang N, Sun G, et al. Metabolically healthy obesity also has risk for hyperuricemia among Chinese general population: a cross-sectional study. Obes Res Clin Pract. 2016 Sep 1;10:S84-S95 ([CrossReff]).

9 Li C, Hsieh MC, Chang SJ. Metabolic syndrome, diabetes, and hyperuricemia. Curr Opin Rheumatol. 2013 Mar 1;25(2):210-216 ([CrossReff]).

10 Lim JS, Mietus-Snyder M, Valente A, Schwarz JM, Lustig RH. The role of fructose in the pathogenesis of NAFLD and the metabolic syndrome. Nat Rev Gastroenterol Hepatol. 2010 May;7(5):251-264 ([CrossReff]).

11 Afzali A, Weiss NS, Boyko EJ, Ioannou GN. Association between serum uric acid level and chronic liver disease in the United States. Hepatology. 2010 Aug;52(2):578-589 ([CrossReff]).

12 Lowe D, Sanvictores T, John S. Alkaline phosphatase. Treasure Island (FL). In: StatPearls. StatPearls Publishing. 2020 [PMID: 29083622].

13 Chen SC, Tsai SP, Jhao JY, Jiang WK, Tsao CK, Chang LY. Liver fat, hepatic enzymes, alkaline phosphatase and the risk of incident type 2 diabetes: a prospective study of 132,377 adults. Sci Rep. 2017 Jul 5;7(1):1-9 ([CrossReff]).

14 Pelluri R, Kongara S, Chimakurthy J, Mahadevan S, Nagasubramanian V. The role of body mass index or metabolic syndrome components causing depression in women: an observation from weight reduction clinical trial. J Clin Pharm Therapeut. 2021:00: 1-7 ([CrossReff]).

15 Peng K, Mo Z, Tian G. Serum lipid abnormalities and nonalcoholic fatty liver disease in adult males. Am J Med Sci. 2017 Mar 1;353(3):236-241 ([CrossReff]).

16 Marchesini G, Bugianesi E, Forlani G, et al. Nonalcoholic fatty liver, steatohepatitis, and the metabolic syndrome. Hepatology. 2003 Apr;37(4):917-923 ([CrossReff]). 